\title{
RELATORIO DO ANNO DE 1921
}

\author{
Exm. ${ }^{\circ}$ Snr.
}

Cumprindo o disposto na letra $i$ do art. 114 do decreto n. 11.530, de 18 de Março de 1915, e no n. XVII, do art. 9..$^{\circ}$ do Regimento Interno desta Faculdade, passo a fazer o relatorio minucioso de tudo quanto occorreu neste estabelecimento a respeito da or:dem, disciplina, serviço miditar, observancia das leis e do orçamento do anno lectiv. de 1921.

Abertura dos trabalhos - Na fórma do disposto no art. 74 do decreto n. 11.530, de 18 de Março de 1915 e do art. 143 do Regimento Interno desta Faculdade, os trabalhos deste Instituto de ensino abriram-se no dia $1 .^{\circ}$ de Março, cedebrando a Congregação dos professores, nesse dia, a sua primeira reunião.

Presença dos professores - Na primeira reunião da Congregação do anno lectivo findo, realizada a $1 .^{\circ}$ de Março, foi verificado que se achavam promptos para o curso os professores Doutores Uladislau Herculano de Freitas, Antonio Amancio Pereira de Carvalho, Antonio Januario Pinto Ferraz, Manoel Pedro Villaboim, José U1piano Pinto de Souza, Gabriel José Rodrigues de Rezende, Candido Nazianzeno Nogueira da Motta, Frederico -Vergueiro Steidel, Jøão Braz de Oliveira Arruda, Luiz Barbosa da Gama Cerqueira, Estevam de Araujo Almeida, Mancel Pacheco Prates, Manoel Aureliano de Gusmão, Theophilo Benedicto de Souza Carvalho e José Joaquim Cardozo de Mello Neto, e os substitutos, na regencia de cadeiras, Raphael Corrêa de Sampaio e Braz de Sousa Arruda, e os substitutos que não regem cadeiras Drs. Spencer Vampré, José Augusto Cesar, Octavio Mendes, 
Francisco Antonio de Almeida Morato e José de Alcantara Machado d'Oliveira.

Exame vestibular - Na fórma do art. 62 do Regimento Interno, a inscripção para o exame vestibular, instituido pelo art. 77, letra $c$ do decreto n. ${ }^{\circ} 11.530$, de 18 de Março de 1915, para a matricula no curso desta Faculdade, aberta a 2 de Janeiro e encerrada a 12 do mesmo mez, e, reaberta a 4 de Märço, de conformidade com o disposto no art. 2. do decreto $n .^{\circ} 4.282$, de Dezembro dé 1920 e resolução do Conselho Superior do Ensino, tomada em sessãa de 23 de Fevereiro anterior, foi encerrada a 15 do mesmo mez, tendo a ella concorrido sessenta e seis (66) 'candidatos, sendo na primeira epoca 42 e na segunda 24 . $O$ exame iniciou-se com a prova escripta, para os inscriptos na primeira epoca, no dia 17 de Janeiro, tendo terminado no dia 31 do mesmo mez; e, para os inscriptos na 2. ${ }^{2}$ epoca, no dia 29 de de Março, tendo terminado no dia seguinte, 30 do mesmo mez. 0 resultado do julgamento desse exame foi o seguinte: Em Janeiro, approvados 32 , inhabilitados 7 e reprovados 3 , total 42 ; e em Março, approvados 3, inhabilitados 14 e reprovados 7, total 24. (Annexo respectivo). A commissão julgadora desse exame foi constituida, na sessão da Congregação, realizada a 21 de Dezembro de 1920, dos Drs. Frederico Vergueiro Steidel, João Braz de Oliveira Arruda, Estevam de Araujo Almeida, Manoel Aureliano de Gusmão, Theophilo Benedicto de Souza Carvalho e José Augusto Cesar. Horario dás aulas - Pela Congregação dos professores, em sessão realiżada a $1 .^{\circ}$ de Março, foi adoptado o Horario constante do annexo respectivo.

Programmas de! ensino - Adoptados pelos professores das cadeiras do cursó, foi nomeada uma commissão composta dos Drs. Frederico Vergueiro Steidel, João Braz de Oliveira Arruda e Manoel Aureliano de Gusmão, a qual formulou o seu parecer, opinando pela approvação, pa- 
recer esse que foi approvado na mesma sessão de $1 .^{\circ}$ de Março. Os programmas foram impressos e postos á venda na Thesouraria da Faculdade.

Designação de professores - No correr do anno findo, foram designados os professores: Dr. José Joaquim Candozo de Mello Neto, professor cathedratico, para preencher o logar vago de professor substituto da 5. ${ }^{a}$ secção; Dr. Spencer Vampré, substituto da $1 .^{a}$ secção, para preencher o logar de substituto da 5. ${ }^{a}$ secção, que se acha vago, em substituição ao Dr. José Joaquim Cardozo de Mello Neto; para reger a $3 .^{a}$ cadeira do $1 .^{\circ}$ anno, em substituição ao Dr. Reynaldo Porchat e a 4." cadeira do 5." anno, em substituição ao Dr. Manoel Pedro Villaboim; Dr. Braz de Sousa Arruda, substituto da 2." secção, para reger a $2 .^{\text {a }}$ cad. do $1 .^{\circ}$ anno, em substituição ao Dr. Uladislau Herculano de Freitas e a $1 .^{a}$ cad. do $2 .^{\circ}$ anno, cujo logar ainda não está preenchido; Dr. Raphael Corrêa Sampaio, substituto da 4 . $^{\mathrm{a}}$ secção, para reger a 2 . $^{\mathrm{a}}$ cad. do 4. ${ }^{\circ}$ anno, em substituição ao Dr. Luiz Barbosa da Gama Cerqueira e a 2. ${ }^{a}$ cad. do 5..$^{\circ}$ anno, em substituição, ao Dr. José Manoel de Azevedo Marques; Dr. Octavio Mendes, substituto da 6. ${ }^{\mathrm{a}}$ secção, para reger a $1 .^{\mathrm{a}}$ cad. do $3 .^{\circ}$ anno, em substituição ao Dr. Gabriel José Rodrigues de Rezende, e Dr: Francisco Antonio de Almeida Morato, substituto da 7. ${ }^{\text {a }}$ secção, para reger a $2 .^{a}$ cad. do $2 .^{\circ}$ anno, em substituição ao Dr. José Joaquim de Mello Neto.

Inscripção para exames da segunda epoca - Para os exames da 2. ${ }^{\mathrm{a}}$ epoca, inscreveram-se 84 alumnos, sendo: no $1 .^{\circ}$ anno 9 , no $2 .^{\circ} 32$, no $3 .^{\circ} 9$, no $4 .^{\circ} 15$ e no $5 .^{\circ} 19$. 0 resultado desses exames, consta do annexo respectivo.

Inscripção de matricula - Matricularam-se nos cinco annos do curso, 362 alumnos, sendo: no $1 .^{\circ}$ anno 63 , no $2 .^{\circ}$ 53 , no $3 .^{\circ} 123$, no $4 .^{\circ} 43$ e no $5 .^{\circ} 80$.

Transferencia de matricula - Durante o periodo das ferias, somente um alumno do $2 .^{\circ}$ anno requereu e obteve 
guia de transferencia para a Faculdade de Direito do Estado de Minas Geraes.

Licença - Durante o anno lectivo findo, estiveram no gozo de licença, o Dr. Reynaldo Porchat, cathedratico da 3." cad. do 1." anno, de 17 de Agosto a 16 de Novembro; o Dr. Gabriel José Rodrigues de Rezende, cathedratico da 1." cad. do 3." anno, de 11 de Julho a 2 de Agosto e de 18 de Agosto a 17 de Outubro; o Dr. Luiz Barbosa da Gama Cerqueira, cathedratico da 2." cad. do 4. ${ }^{\circ}$ anno, de 6 a 19 de Dezembro; o Dr. José Joaquim Cardozo de Mello. Neto, cathedratico da 2. ${ }^{a}$ cad. do 2." anno, de 1.1 de Julho a 9 de Agosto; e o bedel Abilio Pereira de Oliveira, de 6 de Outubro a 18 de Novembro.

Fallecimento - No dia $10^{\circ}$ de Agosto, falleceu o porteiro Narcizo Antonio Coelho Netto.

Exoneraçã̃o - No dia 26, de Setembro, foi exonerado a seu pedido, o bedel Ignacio Vieira Marcondes.

Nomeações e posse de empregados - Por portaria de 16 de Agosto, desta Directoria, para o logar de porteiro, na vaga verificada com o fallecimento de Narcizo Antonio Coelho Netto, foi nomeado o bed'el Pedro Dias da Silva, que tomou posse e entrou em exercicio nessa mesma data; para o logar de bedel, na vaga verificada com a nomeação e posse do porteiro Pedro Dias da Silva, por portaria de 16 de Ágosto, desta Directoria, foi nomeado o servente José Martinho de Moura Baptista, que tomou posse e entrou em exercicio desse cargo, nessa mesma data, e, para o logar de bedel, na vaga verificada com a exoneração de Ignacio Vieira Marcondes, por portaria desta Birectoria, de 26 de Setembro, foi nomeado o servente Vicente Personal, que tomou posse e entrou no exercicio desse cargo, nesse mesme dia.

Substituições - No correr do anno lectivo findo, o Drr. Antonio Amancio Pereira de Carvalho, professor cathedratico mais antigo e vice-Director, na fórma da lei, 
sabstituiu ao Dr. Uladislau Herculano de Freitas, no exercicio do eargo de Director, de $\mathrm{k6}$ de Julho a 13 de Agosto; o Dr. José Joaquim Cardozo de Mello Neto, cathedratico, de 15 de Abril a 10 de Julho, substituiu ao Dr. Manoel Pedro Villaboim, na regencia da 4.' cad. do 5. anno; o Dr. Spencer Vampré, substituto da $1 .{ }^{a}$ secção, de 16 de Julho a 16 de Novembro, substituiu ao Dr. Reynaldo Porchat, na regencia da $3 .^{\text {a }}$ cad. do $1 .^{\circ}$ anno, de 16 de Julho a 31 de Dezembro, substituiu ao Dr. Manoel Pedro Villaboim, na regencia da $4 .^{2}$ cad. do $5 .^{\circ}$ anno; o Dr. Braz de Souza Arruda, substituto da $2 .^{d}$ secção, de 16 de Julho a 13 de Agosto, substituiu ao Dr. Uladislau Herculano de Freitas, na regencia da 2." cad. do $1 .^{\circ}$ anno; o Dr. Raphael Corrêa de Sampaio, substituto da 4." secção, de 1." de Janeiro a 31 de Dezembro, substituiu ao Dr. José Manoel de Azevedo Marques, na regencia da $2 .^{a}$ cad. do 5 . anno, e, de 6 a 19 de Dezembro, substituiu ao Dr. Luiz Barbosa da Gama Cerqueira, na regencia da $2 .^{\prime \prime}$ cad. do $4 .^{\circ}$ anno; o Dr. Octavio Mendes, substituto da $6 .^{a}$ secção, de 11 de Julho a 2 de Agosto, substituiu ao Dr. Gabriel José Rodrigues de Rezende, na regencia da 1 . cadeira do $3 .^{\circ}$ anno ao Dr. Francisco Antonio de Almeida Morato, substituto da 7 " secção, de 11 de Julho a 9 de agosto, substituiu ao Dr. José Joaquim Cardozo de Mello Neto, na regencia da 2." cadeira do $2 .^{\circ}$ anno; o servente Vicente Personal, de 9 a 25 de Agosto, substituiu ao bediel Ignacio Vieira Marcondes, e o servente Victor da Silva, de 6 de Outubro a 18 de Novem. bro, substituiu ao bedel Abilio Pereira de Oliveira.

Serviço Publico - Durante o anno lectivo, estiveram ausentes desta Faculdade, por motivo de serviço publico, o Dr. Uladislau Herculano dẻ Freitas, Director e cathedratico, de 16 de Julho a 13 de Agosto, no Conselho Superior do Ensino, comø representante desta Faculdade; o Dr. Manoel Pedro Villaboim, de 15 de abril a 31 de Degenabro, com assento no. Congresso Nacional, como Deputado pelo 
Estado de São Paulo; o. Dr. José Manoel de.Azevedo Marques, de $1 .^{\circ}$ de Janeiro a 31 de Dezembro, como Ministro das Relações Exteriores, e o Dr. Reynaldo Porchat, de 16 de Julho a 13 de Agosto, no Conselho Superior do Ensino, como representante desta Faculdade.

Premio - A Congregação dos professores, em sessão realizada a 18 de Abril, classificou' o bacharel Americo Brasiliense Antunes de Moura como o alumno que maior numero de notas distinctas obteve, isto é, dezoito (18) distincções, no quinquennio de 1916 a 1920, para lhe ser conferido o Premio "Rodrigues Alves", consistente no pagamento dos juros das treze (13) apolices estaduaes, no anno 1920, em que concluiu o seu curso academico.

Defeza de theses - Conforme fôra resolvido na sessão da Congregação de 21 de Dezembro de 1919, nos dias 11 a 12 de Abril do anno findo, realizou-se a defeza de theses de um candidato ao grau de Doutor em Sciencias Juridicas e Sociaes, do bacharel Noé Azevedo, diplomado por esta Faculdade, o qual se inscreveu no dia 9 de Junho de 1920, como consta do relatorio desse mesmo anno, tendo sido esse candidato approvado simplesmente com os votos dos Drs. Gabriel José Rodrigues de Rezende, Reynaldo Porchat, Luiz Barbosa da Gama Cerqueira e Raphael Corrêa de: Sampaio, contra os votos dos Drs. Antonio Amancio Pereira de Carvalho, Estevam de Araujo Almeida e Manoel Pacheco Prates, que votaram para a approvação plena. A commissão examinadora, como consta do Relatorio de 1920, ficou composta dos professores Drs. Reynaldo Porchat, do $1 .^{\circ}$ anno, Manoel Pacheco Prates, do 2. , Luiz Barbosa da Gama Cerqueira, do 3. ${ }^{\circ}$, Estevam de Araujo Almeida, do $4 .^{\circ}$ e Raphael Corrêa de Sampaio, do 5., além do Dr. Antonio Amancio Pereira de Carvalho, professor de Medicina Publica, do 5. ${ }^{\circ}$ anno. Nesse trabalho de defeza de theses foram cumpridas as disposiçóes 
do decreto n. 11.530, de 18 de Março de 1915 e do Regimento Interno desta Faculdade.

Inscripção para defeza de theses - No dia 14 de Dezembro findo, inscreveram-se para revalidação de diplomas conferidos por Faculdades extrangeiras, os srs. Amilcar Mendes Gonçalves, diplomado pela Faculdade de Direito de Paris, e Antonio Gomes do Amaral Filho, diplomado pela Oriental University, de Washington, districto de Columbia, dos Estados Unidos da America do Norte, os quaes, no dia 15 do mesmo mez sortearam e escolheram os pontos das cadeiras de direito positivo e a de Direito Publico e Constitucional, sobre os quaes cada um delles terá de formular as suas theses e dissertações. No dia 21 seguinte, a Congregação nomeou a commissão composta dos professores Drs. Candido Nazianzeno Nogueira da Motta, Gabriel José Rodrigues de Rezende el Frederico Vergueiro Steidel, para examinar e approvar as theses apresentadas por esses dois candidatos, sendo designado o dia 25 de Fevereiro proximo para a apresentação das theses de ambos os candidatos inscriptos.

Acquisição de apolices federaes - Por esta Directoria foram adquiridas, durante o anno findo, cincoenta e sete (57) apolices da divida publica da União, do valor de um conto de réis $(1: 000 \$ 000)$, cada uma, para a constituição do patrimonio desta Faculdade.

Eleição do representante da Congregação junto ao Conselho Superior do Ensino - Em sessão da Congregação, realizada a 18 de Abril, se procedeu á eleição do representante da mesma Congregação junto ao Conselho Superior do Ensino, para o biennio de 1921 a 1923, tendo sido reeleito o Dr. Reynaldo Porchat, que obteve quatorze votos (14), contra um (1), dado ao Dr. Frederico Vergueiro Steidel.

Inscripção para exames da primeira epoca - Para estes exames inscreveram-se 293 alumnos, sendo no $1 .^{\circ}$ 
anno 44 , no $2 .^{\circ} 44$, no $3 .^{\circ} 94$, no $4 .^{\circ} 38$ e no $5 .^{\circ} 73$. O resultado desses exames consta do annexo respectivo.

Collação de grau - Durante o anno findo, foi collado o grau de Doutor em Sciencias Juridicas e Sociaes, a um bacharel em Sciencias Juridicas e Sociaes, formado por esta Faculdade e nella approvado em defeza de theses, o qual é natural do Estado de Minas Geraes, e o de bacharel em Sciencias Juridicas e Sociaes a noventa e dois (92) bacharelandos, dos quaes um (1), concluiu o seu curso na primeira epoca do anno lectivo de 1920, vinte e quatro (24) o concluiram na segunda epoca de 1920, isto é, em Março de 1921, e os restantes sessenta e sete (67 o concluiram na primeira epoca do anno lectivo findo. Desses noventa e dois (92) bachareis, sessenta e tres (63) são naturaes do Estado de São Paulo, seis (6) do Estado de Minas Geraes; tres (3) da Cidade do Rio de Janeiro; tres (3) do Estado de Pernambuco; dois (2) do Estado do Pará; um (1) do Estado do Amazonas; um (1) do Estado do Piauhy; um (1) do Estado do Rio de Janeiro; um (1) do Estado do Paraná, um (1) do Estado de Goyaz e um (1) do Reino da Italia, e respectivo annexo.

Cartas de bacharel - Durante o anno findo, foram expedidas oitenta e tres (83) cartas a egual numero de bachareis formados em Sciencias Juridicas e Sociaes por esta Faculdade. Desses oitenta e tres (83) bachareis, são naturaes do Estado de São Paulo sessenta e tres (63); do Estado de Minas Geraes seis (6); do Estado do Pará quatro (4); do Estado do Paraná dois (2); do Estado de Santa Catharina dois (2); do Estado do Rio Grande do Norte um (1); do Estado do Piauhy um (1); do Estado de Goyaz um (1); do Estado do Rio de Janeiro um (1), e do Reino da Italia dois (2). Annexo respectivo.

Serviço militar - De conformidade com a informação prestada pelo respectivo instructor, durante o anno 
findo, frequentaram a instrucção militar apenas quinze (15) alumnos, dos quaes foram: approvado 1, e reprovados oito (8), não tendo comparecido ao exame seis (6).

Sessões da Congregação - No correr do anno findo, a Congregação dos professores celebrou seis (6) sessões, nas quaes foram tratados diversos assumptos.

Procedimento dos alumnos - $\mathrm{O}$ procedimento dos alumnos, no correr do anno lectivo findo, foi bom, nada tendo occorrido digno de menção.

Bibliotheca - A Bibliotheca desta Faculdade foi frequentada, durante o anno findo, por 6.763 pessôas, que consultaram 2.355 obras, em 4.705 volumes, sendo em portuguez 1761, em francez 355, em italiano 161, em hespanhol 31, em inglez 27 e em latim 20, estando no numero dos consulentes incluidos 3.109 pessôas, que leram jornaes e revistas. No correr do anno, entraram para a Bibliotheca 618 obras, em 1.055 volumes, sendo por compra 558 obras, em 814 volumes, e, por doação 60 obras, em 241 volumes, tendo sido encadernadas 142 obras, em 394 volumes. (Annexo respectivo.)

Os empregados da Bibliotheca bem cumpriram o seu dever.

Thesouraria - $\mathrm{O}$ balanço demonstrativo da Thesouraria desta Faculdade, constante do annexo respectivo, fechado a 31 de Dezembro findo, accusa que, da Receita e Despeza, ha um saldo de seiscentos e quarenta e quatro contos cinco mil e sessenta e sete réis (644:005\$067), assim distribuido: dinheiro em Caixa, dois contos quinhentos e dezenove mil trezentos sessenta e sete réis $(2: 519 \$ 367)$; no Banco de Commercio e Industria de São Paulo, cento e quarenta e sete contos trezentos e vinte e tres mil e quinhentos réis (147:323\$500), no Banco do Brazil, setenta e um contos cento sessenta e dois mil e duzentos réis (71:162\$200) e quatrocentos e vinte tres contos de réis 
(423:000\$000), em quatrocentos e vinte tres apolices federaes do valor de um conto (1:000\$000), cada uma.

O saldo apurado em 1920 foi de quinhentos e noventa e cinco contos novecentos e dezenove mil e setecentos réis $(595: 919 \$ 700)$, havendo, portanto, uma differença a mais de quarenta e oito contos oitenta e cinco mil trezentos e sessenta e sete réis (48:085\$367).

O Thesoureiro bem cumpriu os seus deveres.

Secretaria - Os serviços da Secretaria estiveram sempre em dia, tendo todos os empregados bem cumprido os seus deveres.

Secretaria da Faculdade de Direito de São Paulo, em 20 de Janeiro de 1922.

O Director:

Uladislau Herculano de Freitas 